\title{
the Dynamic Portfolio Strategy employing the Investor Sentiment under Stochastic Environment
}

\author{
Qian Feng ${ }^{1}$, Ting $\mathrm{Li}^{1}$, and Zhenyong $\mathrm{Li}^{1}$ \\ ${ }^{1}$ Ningxia University
}

May 29, 2020

\begin{abstract}
Several kinds of research have proved that the overall investor sentiment has a non-negligible impact on the return of the stocks. Meanwhile, there exist many irrational elements in the overall investor sentiment. However, little research has been conducted on how rational investors can better arrange their investment strategies in the face of this complex situation. Our manuscript explores the dynamic optimal portfolio of the returns of the stock affected by the sentiment of the investors. Applying the approach of the stochastic control, the HJB equation of the final wealth is constructed. Hence, the optimal investment strategy and the effective frontier are obtained employing the Legendre transformation and the duality theory. An illustrative example is provided to support our theoretical model. Taking into account the overall investor sentiment and its irrational components, a rational investor would do not invest so much in the stocks during the periods of the negative sentiment or the period of being excessively positive sentiment. Furthermore, the sentiment-adjusted mean-variance relation has been derived from our model that still adopts the principle of the Security Market Line (SML).
\end{abstract}

\section{Hosted file}

The Dynamic Portfolio Strategy employing the Investor Sentiment under Stochastic Environment.doc available at https://authorea.com/users/327815/articles/455240-the-dynamic-portfoliostrategy-employing-the-investor-sentiment-under-stochastic-environment 

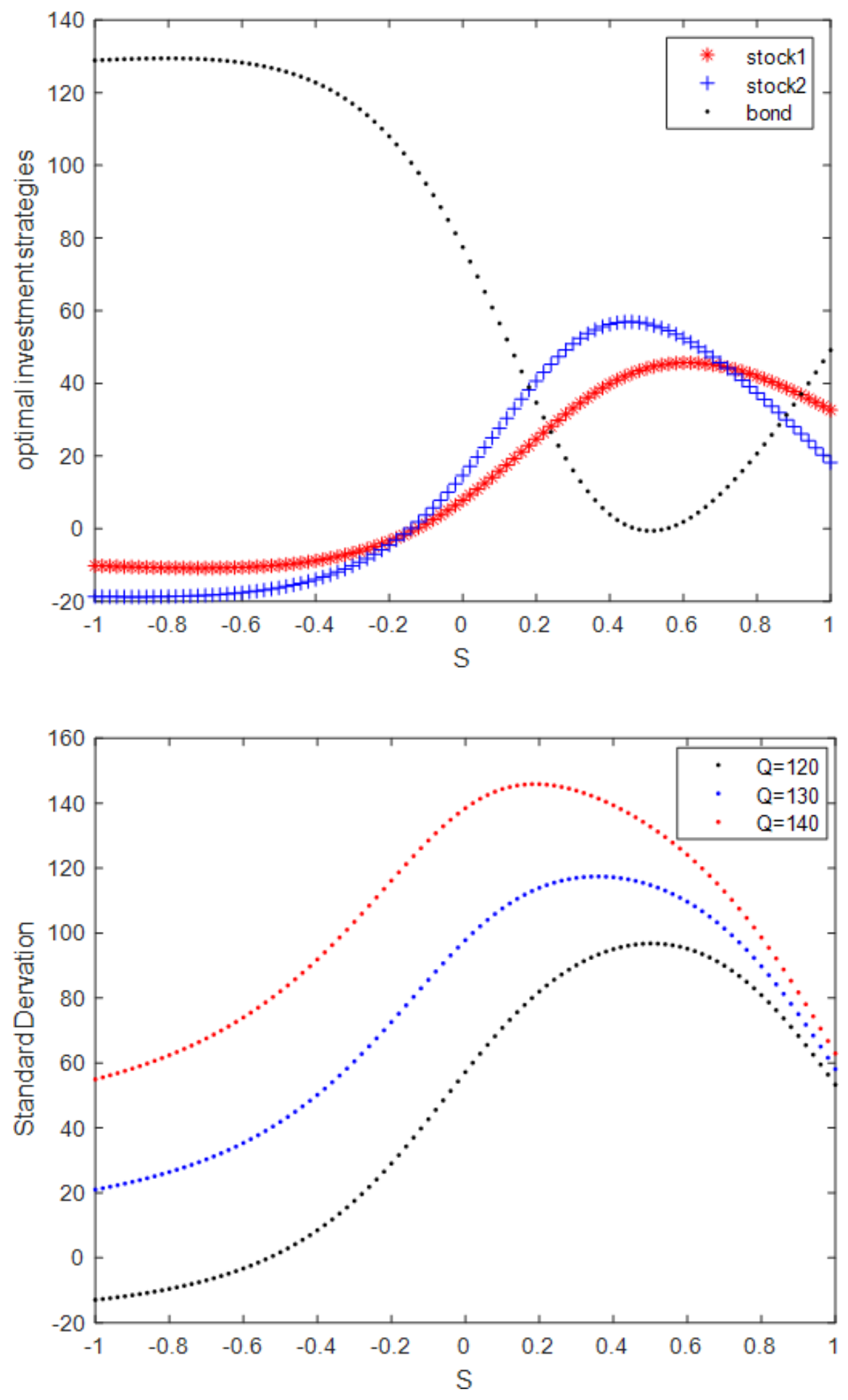